\title{
Recurrent haematuria; a rare presentation of 46XX Congenital adrenal hyperplasia presenting late and reared as males - two cases
}

\author{
D Karuppiah¹, P Pathirana1, S Dilakkumar ${ }^{1}$, A S Pallewatte ${ }^{2}$, M Pravinson ${ }^{1}$, M Mithusha $^{1}$ \\ 1 Teaching Hospital Batticaloa \\ ${ }^{2}$ National Hospital Sri Lanka
}

Copyright: This is an open-access article distributed under the terms of the Creative Commons Attribution License, which permits unrestricted use, distribution, and reproduction in any medium, provided the original author and source are credited (CC BY 4.0)

\section{Abstract}

Congenital adrenal hyperplasia $(\mathrm{CAH})$ is a group of inherited autosomal recessive disorders characterized by a defect in enzymes involved in biosynthesis of cortisol, aldosterone or both. We report two patients presented with recurrent haematuria with two different forms of $\mathrm{CAH}$ who presented late and reared as males. We describe the challenges posed on managing them and how the quality of life will be improved by offering hormonal and surgical remedies without changing or reassigning the gender to females.

Key words: Congenital adrenal hyperplasia, gender assignment, recurrent haematuria, 21-hydroxylase, 11-beta hydroxylase

\section{Introduction}

Congenital adrenal hyperplasia $(\mathrm{CAH})$ is a group of inherited autosomal recessive disorders characterized by a defect in enzymes involved in biosynthesis of cortisol, aldosterone or both (1). The commonest type is 21hydroxylase $(21-\mathrm{OH})$ deficiency accounting for 90 to $95 \%$. The second commonest type is 11-beta hydroxylase deficiency (6-8\%) (2). In CAH loss of negative feedback from cortisol results in ACTH hypersecretion, and adrenocortical hyperplasia (3). Accumulation of steroid precursors above the enzyme deficiency shunted into androgen synthesis pathway will result in androgen excess (Figure 1). The clinical presentation depends on severity of mutation and this vary from neonatal salt wasting, virilisation to non-classic $\mathrm{CAH}$ in adulthood. The degree of virilisation in a female CAH (46XX) also vary from nearly female looking external genitalia to completely male looking ones with prader stages $2-5$. In these cases, if the diagnosis is made early during infancy, gender assignment as female is not debatable. When presented later and already reared as males and presenting with late complications such as haematuria, gender reassignment and management is highly challenging.
The following describes two adults with 2 different forms of $\mathrm{CAH}$ presenting very late with recurrent haematuria and the challenges posed on managing them.

\section{Patient S}

A 36 year-old man presented to the surgical clinic with intermittent painless hematuria for last 2 years. He was referred to Endocrinology unit for short stature and gynaecomastia. His childhood and family history was unavailable. Until this admission, no expert medical help had been sought for his short stature. He was single and working as a manual labourer. His height was $137.5 \mathrm{~cm}$ and weighed $46 \mathrm{~kg}$ with body mass index of $26 \mathrm{~kg} / \mathrm{m} 2$. He had bilateral breast enlargement with no male pattern body hair. Genital examination showed tanner 3 staging for pubic hair and hypospediasis with meatus at mid shaft of phallus. Testes were not palpable in the underdeveloped scrotal sac (figure 1). His blood pressure was $120 / 80 \mathrm{mmHg}$ and rest of the examinations were unremarkable. His karyotype was 46XX. He had elevated 17 hydroxy-progesterone (17 OHP) with slightly elevated testosterone. Although his basal cortisol was normal, the level after ACTH stimulation was suboptimal. Laboratory tests are described in table 1 . Imaging with CT showed enlarged left adrenal gland $(3.2 \times 3.3 \mathrm{~cm})$, 
uterus and ovaries. The diagnosis of $\mathrm{CAH}$ (21 hydroxylase deficiency) was made and this complexity and consequences of the pathology could have on the patient's life were explained. Knowing the fact that his fertility will not be possible as a male, he decided to keep his sex allocation as male. He underwent surgical removal of the uterus, ovaries, upper third of the vagina and fallopian tubes under steroid cover (figure 2). Bilateral mastectomy was planned and the possibility of staged male genitoplasty comprising of chordee correction, male urethroplasty and insertion of artificial testicular prosthesis in the labioscrotal sac was discussed with the patient. He was advised on the need for steroid cover during severe illness and surgery and steroid alert card was given. Monthly testosterone replacement was started.

Patient informed consent and permission to use these views was granted in accordance with recognised guidelines on the ethics of such photography.
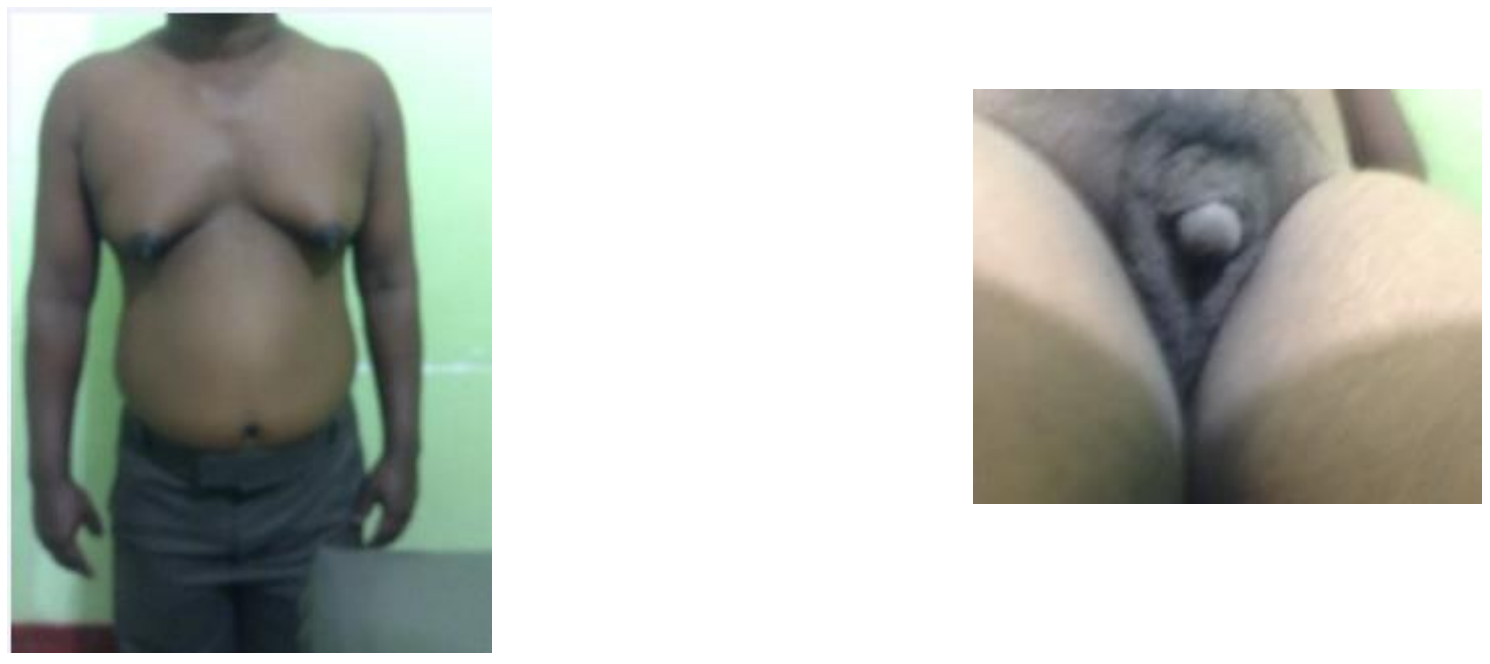

Figure 1: Patient with Congenital adrenal hyperplasia showing short stature, breast enlargement and ambiguous genitalia

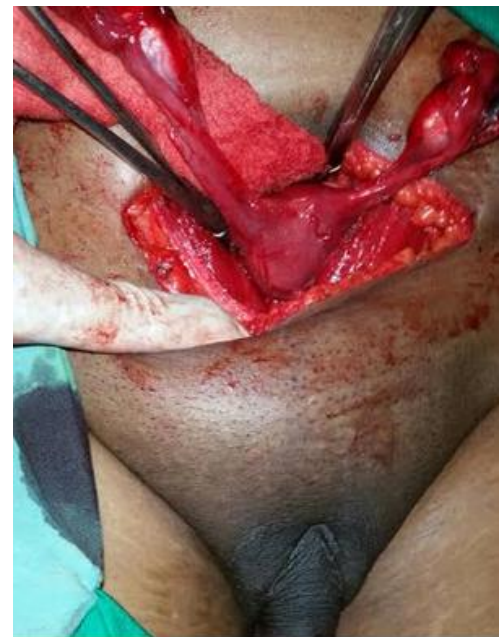

Figure 2: Uterus and adnexa being removed in the patient with congenital adrenal hyperplasia and reared as male

Patient RA 23 years old man was transferred from a local hospital with the history of abdominal pain, haematuria and high blood pressure. He was the third child of nonconsanguineous parents from a very low socio economic background. He had been admitted to the local hospital at the age of fifteen with headache and haematuria. At that time he was treated for hypertension and followed up for few months. Three years ago he was re admitted with painful genitalia and haematuria associated with clots especially at the end of the micturition. This time he 
was transferred to National hospital of Sri Lanka for further evaluation for short stature \& haematuria. While investigating he dropped out from follow-up. He had 4 healthy siblings. He was average in school performance; studied up-to grade 9. But he dropped out from school due to bullying related to his short stature. At admission to local hospital he was hypertensive with a blood pressure of $240 / 120 \mathrm{mmHg}$. He was very short with a height of $130 \mathrm{~cm}$ and weighed $36.2 \mathrm{~kg}$ (body mass index of $21.42 \mathrm{~kg} / \mathrm{m} 2)$. There was no cutaneous hyperpigmentation. He had male pattern facial and body hair. His genitals were tanner staging 4 for pubic hair, with phallus length of $4 \mathrm{~cm}$. He had distal hypospadias with sub-coronal meatus. Scrotum was not well formed and testes were not palpable (figure 4). He had hypertensive retinopathy changes with silver wiring.

Karyotype was 46XX and was negative for SRY gene. Biochemistry and endocrine investigations are shown in table 1. He had elevated $17 \mathrm{OHP}$ and testosterone levels. His basal as well as ACTH stimulated cortisol levels were very low indicating adrenal insufficiency. Imaging with ultrasound scan showed rudimentary uterus and MRI showed enlarged adrenals with cystic areas, uterus with bilateral small ovaries.

The diagnosis of CAH (11 beta hydroxylase deficiency) was made based on available clinical and biochemical findings. The levels of 11-deoxycortisol and ACTH were not measured due to availability problems in the region. Similar to previous patient, he also decided to keep his sex allocation as male. Surgical removal of the uterus, ovaries, upper third of the vagina and fallopian tubes and bilateral mastectomy was planned and the possibility of staged male genitoplasty comprising of chordee correction, male urethroplasty and insertion of artificial testicular prosthesis in the labioscrotal sac was discussed with the patient. He was advised on the need for long term therapy with steroid and steroid alert card was given. Monthly testosterone replacement was started along with hydrocortisone and anti-hypertensives.

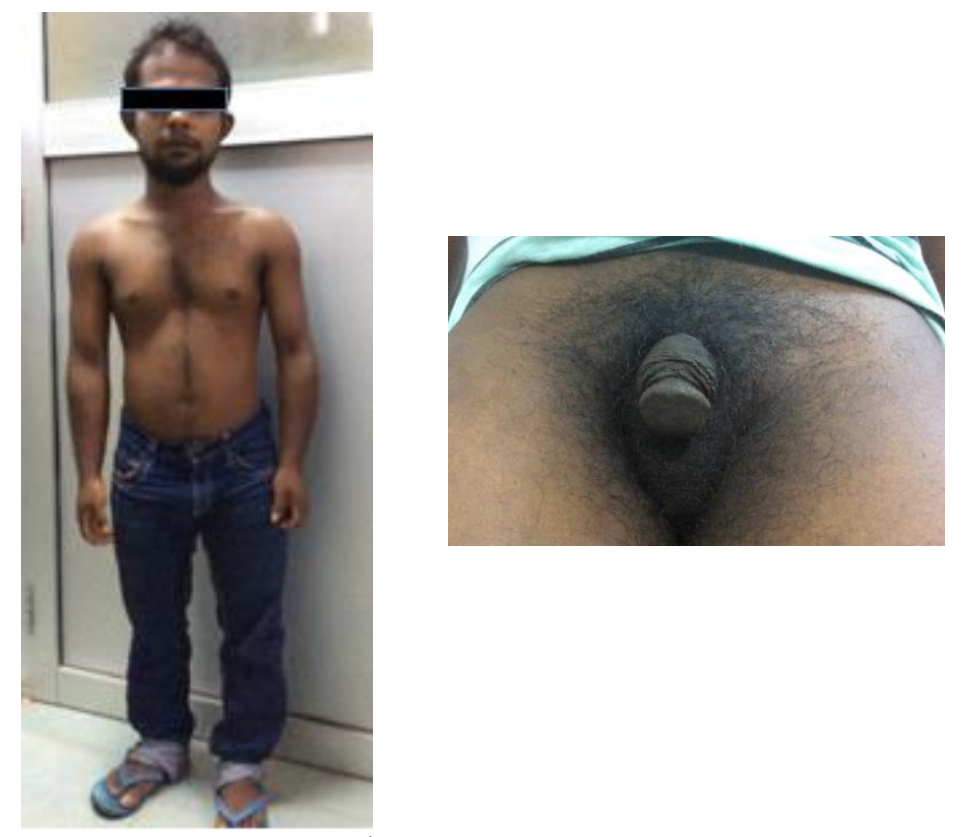

Figure 4

Table 1. Laboratory investigations of the patients with congenital adrenal hyperplasia

\begin{tabular}{llll}
\hline Test & Patient $\mathbf{S}$ & Patient R & Reference Value \\
\hline Total testosterone $(\mathrm{ng} / \mathrm{ml})$ & 1.87 & 3.8 & $0.3-1.2$ \\
$\begin{array}{l}\text { 17 OHP - basal } \\
\text { 17 OHP, } 60 \text { min post synacthen }\end{array}$ & 14 & 12.8 & $<5$ \\
$(\mathrm{nmol} / \mathrm{L})$ & 93.06 & 93 & $<30$ \\
DHEA-sulphate $(\mu \mathrm{g} / \mathrm{ml})$ & 4.2 & 5.4 & $0.9-3.6$ \\
\hline
\end{tabular}




\begin{tabular}{llll}
\hline $\mathrm{LH}(\mathrm{mIU} / \mathrm{L})$ & 12.2 & 3.72 & $2-20$ \\
FSH $(\mathrm{mIU} / \mathrm{L})$ & 9.72 & 5.4 & $2-20$ \\
Free T4 $(\mathrm{ng} / \mathrm{dl})$ & 1 & 1.7 & $0.9-1.7$ \\
TSH $(\mu \mathrm{IU} / \mathrm{ml})$ & 3.52 & 3.3 & $0.3-4.20$ \\
Cortisol $(\mathrm{nmol} / \mathrm{l})$ & 252 & 60 & $123-626$ \\
basal & & & \\
Cortisol -30 min post synacthen & 382 & 64.5 & $>550 \mathrm{nmol} / 1$ \\
(nmol/l) & & & \\
FBS $(\mathrm{nmol} / \mathrm{l})$ & 4.6 & 4.3 & $3.9-5.5$ \\
Serum K+ (mmol/l) & 4 & 3 & $3.5-5.3$ \\
Serum Na+ (mmol/l) & 137 & 135 & $135-148$ \\
Serum creatinine $(\mathrm{mg} / \mathrm{dl})$ & 0.87 & 0.9 & $0.6-1.2$ \\
Serum calcium $(\mathrm{mmol} / \mathrm{l})$ & 2.21 & 2.18 & $2.1-2.55$ \\
Albumin $(\mathrm{g} / \mathrm{L})$ & 4.2 & 3.7 & $3.5-5.5$ \\
\hline
\end{tabular}

\section{Discussion}

Gender identity is the sense of belonging that one feels for a particular sex psychologically and socially independent of one's biological sex. Gender assignment become very complex if the genitalia are highly virilised. Apart from karyotype, sociocultural influences and parental expectations play a significant role in this. There is scarcity of data on gender identity among females with $\mathrm{CAH}{ }^{(4)}$. Some studies showed among 46XX CAH, only a minority developed gender dissatisfaction when reared as females, but there are also reports of successful male gender assignments $(5,6)$

These two patients have been raised as boys since birth and they are satisfied with their male gender identity. Although both of them were very short and had ambiguous genitalia, they did not seek medical attention until very late. Cyclical haematuria secondary to uterine bleeding was the main reason for them to seek medical advice. The reason for delayed presentation could be the family's desire for a male child in our sociocultural background or ignorance that early treatment is required. The diagnosis of CAH was made very late in these two patients when they have already had a firm male gender identity and the society and family has accepted them as males. Therefore we offered individualized treatment considering their medical, social and psychological wellbeing.

Management of classic form of $\mathrm{CAH}$ includes replacement of cortisol and aldosterone to control excess androgen symptoms. Treatment of adult patients with $\mathrm{CAH}$ remains controversial due to lack of randomized controlled trials comparing treatment regimens (7). The Endocrine society guidelines recommend glucocorticoid treatment for adult $\mathrm{CAH}$ only individuals with a significant degree of hyperandrogenism or those who desire fertility (8). Hydrocortisone is the drug of choice in children, but in adults, long acting glucocorticoids such as prednisolone and dexamethasone can be used without concern about growth inhibition. Careful individualized therapy to optimize psychological, reproductive and sexual and bone health, avoiding steroid related side effects will benefit adults with $\mathrm{CAH}$.

Although the fertility will not be possible as males in our patients, they could function as normal males with regard to marriage, relationship and occupation. There were few favourable points to these two patients; male gender identity and partial male external body habitus. Moreover they need not to face the legal issues of changes in name and sex on birth certificates and identity cards.

Shilpa Sharma and Devendra Gupta have described seven children with $\mathrm{CAH}$ presented late with severe virilisation and reared as males. In this series patients underwent male genitoplasty and surgical removal of female adnexa. Over the mean follow-up duration of 9.2 years, majority were well adjusted and had good surgical and social outcome, but one had recurrent urinary tract infection and poor social adjustment ${ }^{(6)}$.

Although $\mathrm{CAH}$ patients who presented late have different disease characteristics, the major sex reassignment surgical interventions in the female to male transsexual patients can be utilized for this patients. The main interventions are subcutaneous mastectomy combined with hysterectomy and ovrerectomy and male genitoplasty. The interventions may differ for each patients depending on their degree of virilisation. Creation of a male chest by means of a subcutaneous mastectomy allows the patient to live more easily in the male role. Removal of the female adnexa; uterus, ovaries, fallopian tube and upper vagina will avoid other complications such as uterine bleeding presenting as haematuria like in our two patients. Staged genitoplasty generally comprising of chordee correction, male urethroplasty and scrotoplasty. At a later stage, a testicular prostheses can be inserted (9). They need 
hormonal treatment with testosterone replacement with monitoring of hematocrit and lipid profile.

\section{Conclusion}

Gender assignment in patients with ambiguous genitalia is a complex process especially if there is discordance between genetic and phenotypic characteristics. In patients with 46XX CAH, if the diagnosis is made in early infancy, the sex of rearing is female even the genitalia is fully virilised. However this will be complicated in delayed patients with the concurrent development of masculine identity. Therefore early diagnosis by improving awareness among general physicians is important. In delayed or inadvertent late presentations, the management should be individualized. The quality of life will be improved by offering hormonal and surgical remedies without changing or reassigning the gender to females. This two patients were comfortable with the surgical outcome and willing to undergo further planned surgical interventions.

\section{References}

1. Merke DP, Bornstein SR, Avila NA, Chrousos GP. NIH Conference. Future directions in the study and management of congenital adrenal hyperplasia due to 21-hydroxylase deficiency. Ann Intern Med. 2002, 136 (4): 320-334.

2. Zachmann M, Tassinari D, Prader A. Clinical and biochemical variability of congenital adrenal hyperplasia due to 11-betahydroxylase deficiency. A study of 25 patients. J Clin Endocrinol Metab. 1983;56(2):222-229.

3. Oxford handbook for diabetes endocrinology and metabolism, third edition.

4. Kukreti P, Kandpal M, Jiloha RC. Mistaken gender identity in non-classical congenital adrenal hyperplasia. Indian Journal of Psychiatry. 2014;56(2):182-184. doi:10.4103/0019-5545.130504.

5. Gangaher A, Jyotsna VP, Chauhan V, John J, Mehta M. Gender of rearing and psychosocial aspect in 46 XX congenital adrenal hyperplasia. Indian Journal of Endocrinology and Metabolism. 2016;20(6):870-877. doi:10.4103/2230-8210.192922.

6. Shilpa Sharma and Devendra K. Gupta. Male genitoplasty for 46 XX congenital adrenal hyperplasia patients presenting late and reared as males. Indian J Endocrinol Metab. 2012 Nov-Dec; 16(6): 935-938. doi: 10.4103/2230-8210.102994

7. Merke DP. Approach to the Adult with Congenital Adrenal Hyperplasia due to 21-Hydroxylase Deficiency. The Journal of Clinical Endocrinology and Metabolism. 2008;93(3):653-660. doi:10.1210/jc.2007-2417.

8. Speiser PW, Azziz R, Baskin LS, et al. A Summary of the Endocrine Society Clinical Practice Guidelines on Congenital Adrenal Hyperplasia due to Steroid 21-Hydroxylase Deficiency. International Journal of Pediatric Endocrinology. 2010;2010:494173. doi:10.1155/2010/494173.

9. Monstrey SJ, Ceulemans P, Hoebeke P. Sex Reassignment Surgery in the Female-to-Male Transsexual. Seminars in Plastic Surgery. 2011;25(3):229-244. doi:10.1055/s-0031-1281493. 